Consumer Frustration in the Customer-Server Exchange: The Role of Attitudes toward Complaining and Information Inadequacy Related To Service Failures

Alex M. Susskind

Cornell University

April 7, 2003

Author's Note

Alex M. Susskind (e-mail: ams76@cornell.edu) is assistant professor of Food and Beverage Management at Cornell University’s School of Hotel Administration (Ithaca, NY).

I would like to thank Micki and Chuck Kacmar for their assistance with the LISREL analyses. 


\begin{abstract}
Based on the customer-server exchange, this investigation examines the phenomenon of consumer frustration. Specifically, this investigation examines consumers’ perceptions of frustration as it relates to service failure in service-based transactions. The results indicate that consumers' (a) propensity to complain was related to their perceptions of receiving adequate information in the customer-server exchange regarding service failures, (b) negative attitudes toward complaining was not significantly related to information inadequacy or perceptions of consumer frustration, and (c) perceptions of information inadequacy were significantly related to perceptions of consumer frustration in the customerserver exchange.
\end{abstract}

KEYWORDS: customer service; consumer frustration; service failure; information inadequacy 


\section{Consumer Frustration in the Customer-Server Exchange: The Role of Attitudes toward Complaining and Information Inadequacy Related To Service Failures}

The customer-server exchange is based on a set of expected and realized outcomes between and among consumers and service providers. Research in the hospitality management literature has examined a range of service-related issues ranging from customer complaints, customer satisfaction, and word-ofmouth (WOM) communication (Davidow, 2000; Mount \& Mattila, 2000; Susskind, 2002), to perceived equity and justice in service processes (Collie, Sparks, \& Bradley, 2000; McCollough, 2000), the building of customer-server relationships (Susskind, Borchgrevink, Brymer,\&Kacmar, 2000), and service recovery strategies (Davidow, 2000; Scanian \& McPhail, 2000).

A continued focus on hospitality-based service processes is warranted given that research—old and new (and inside and outside of the hospitality literature)—-has clearly shown that service-focused organizations are different from product focused organizations (Anderson, Fornell,\&Rust, 1997; Day\&Ash, 1979;Day\& Bodur, 1978) and hospitality organizations are a unique type of service-based organization (Susskind, Borchgrevink, Kacmar,\&Brymer, 2000). Because of the growing prevalence of research examining service-based organizations, gaining a better understanding of the customer-server exchange becomes even more important. This is particularly true regarding service failure and service recovery.

In service episodes, communication between the consumer and service provider is a key element in the service delivery process and highlights the need to closely examine the influence of voice-based complaint communication in service organizations. Operators of service-based organizations are aware of the importance of soliciting and managing customer complaints to act as a gauge for their operational performance from the consumers' point of view (Susskind, 2002). When unresolved service failures surface in the customer-server exchange (CSX), consumers' and service providers' goals and expectations have likely been negatively influenced in some manner (Collie et al. 2000; Susskind, 2002). Consistent with the frustration-aggression hypothesis (Berkowitz, 1989; Dollard, Doob, Miller, Mowrer, \&Sears, 
1939), the blocking of goals and objectives in service experiences likely leads to increased perceptions of frustration particularly when the experience with the service is perceived as negative (Averill, 1982).

The CSX offers a unique context to examine frustration because research indicates that frustration emerges from situations in which individuals’ goals or expectations for particular outcomes are thwarted (Berkowitz, 1989; Dollard et al., 1939), and aggression is a likely outcome when frustration remains unchecked. The examination of consumer frustration is a logical extension of the research addressing customer service and customer complaints and is based on the principles of consumer aggression (Fornell \& Westbrook, 1979; Harris, 1974), organizational aggression (Neuman \& Baron, 1998; O’Leary-Kelly, Griffin, \& Glew, 1996; Spector, 1978), information deprivation (Casey, Miller, \& Johnson, 1997), and consumers' attitudes toward service failures and the complaint process (Collie et al., 2000; Day, 1984; McCollough, 2000; Susskind, 2000, 2002).

\section{FRUSTRATION AND AGGRESSION IN ORGANIZATIONAL CONTEXTS}

Reported increases of organizational-based aggression and violence have prompted researchers to begin to examine the antecedents and outcomes of aggression in organizations (Neuman \& Baron, 1998; O’Leary-Kelly et al., 1996; Spector, 1978). Through the application of the generally accepted theories of social learning (Bandura, 1973) and the reformulated frustration-aggression hypothesis (Berkowitz, 1989) researchers have begun to show how frustration and, ultimately, aggression emerge through individuals’ reactions to uncertainty, dissatisfaction, frustration, and goal conflict in work-related, municipal, or social interactions (Tedeschi \& Felson, 1994).

Organizationally motivated aggression can be initiated from an insider or an outsider to the organization (O’Leary-Kelly et al., 1996). Insiders and outsiders typically have different motivations for displays of aggression. These distinctions are particularly important when considering the domain of service-based organizations, as the study of service-based organizations typically involves influences from customers and service providers in the service exchange. Just as in municipal or social situations, a 
single incident or series of related or unrelated incidents in the CSX may thwart one's goals, create frustration, and ultimately act as a trigger for aggressive behavior.

\section{Consumer Frustration}

Consumer frustration is presented here as a negative reaction to aversive treatment or environmental stimuli, rather than an outcome that would be categorized more appropriately as an aggressive or violent reaction (Neuman \&Baron, 1998; O’Leary-Kelly et al., 1996). Specifically, consumer frustration is defined for the purposes of this inquiry as an emotional response to dissatisfying elements of a service experience, making the main focus of this investigation on consumers' perceptions of frustration that emerge from retail service settings. From the customers' viewpoint, waiting on lines, not getting what is requested or paid for, receiving incomplete orders or information regarding products and services offered, and getting a bad attitude from service personnel are all examples of elements that may lead to consumer frustration (Peterson, 2000). Harris (1974) conducted an experiment in which he cut in front of consumers waiting on line for service in banks, restaurants, and other service-based businesses. Harris (1974) reported that the closer the participants were to the front of the line when interrupted (i.e., attaining desired/expected service), the more aggression they displayed. These findings suggest that when an individual's goal to achieve a particular outcome is blocked it is likely that negative outcome will emerge (Averill, 1982; Berkowitz, 1989; Feshbach, 1984). If unchecked, the frustration or anger that remains will likely build until a breaking point is reached. At the breaking point, the individual may display physical and/or verbal aggression toward the object or objects that blocked his or her goal attainment (Averill, 1982; Berkowitz, 1989; Neuman \& Baron, 1998; O’Leary-Kelly et al., 1996). It is also possible, however, that the specific focal point of any displayed aggression played little or no role in creating the frustration that led to the aggressive reaction (Bennett, 1997).

\section{Influences on Consumer Frustration}

In this investigation, three distinct antecedents of consumer frustration regarding service failures are presented (see Figure 1). First, consumers' attitudes toward the complaint process—represented as a propensity to complain and negative attitude regarding complaints—are presented as antecedents of 
information inadequacy in the model (Hypothesis 1 and Hypothesis 2, respectively). Next, consumers' perceived information inadequacy regarding service failures is presented as an antecedent of consumer frustration (Hypothesis 3). Information inadequacy is presented as a mediator of the relationships between the two dimensions of consumers' attitude toward complaints and consumer frustration.

Propensity to complain. In the CSX, a satisfying experience emerges from service episodes when one’s expectations for service are met. Consumers do, however, experience elements in service episodes that do not meet their expectations and lead to dissatisfaction. There are a number of factors that drive consumers' motivation to complain. The decision process for the consumer typically involves (a) a cognitive evaluation of the relevance of the service failure, (b) the consumers' knowledge and experience with similar service-based failures, (c) the specific limitations of complaining in the particular instance, and (d) the likelihood of success in complaining (Day, 1984). Based on these four factors, consumers cognitively process the extent to which they believe that they (a) are able to effectively complain about the dissatisfying situation and (b) believe that their complaint(s) will lead to a desired remedy or expectancy (Singh, 1988; Singh \& Wilkes, 1996; Susskind, 2000). In the aggregate, this schema of the complaint process allows the consumer to form specific attitudes and beliefs toward the act of complaining and assign value to it, making a global attitude toward complaining a collection of many experiences, not one alone.

When a consumer experiences a service failure, the particular service failure will influence the enactment of a complaint schema and will determine whether or not a complaint will be lodged in that instance (a behavior). For example, when purchasing food from a drive-through window at a quick service restaurant, on occasion, the order placed and purchased differs from the order that was received.

When the customer recognizes the service failure after driving away, he or she must make a decision about whether to complain or not in this specific instance based on the complaint schema and the relevant expectancies (Singh, 1988; Singh \& Wilkes, 1996; Susskind, 2000). The consumer may believe that it is important to complain and have a strong positive attitude toward complaining, however his or her schema may indicate that it is impractical to complain in a particular situation (i.e., returning to the 
restaurant to have the takeout order corrected). Although some individuals believe that complaining is a necessary, worthwhile, and important function of consumerism, others do not. As indicated earlier, consumers' attitudes toward complaining are separate from the physical act of lodging a complaint (a behavior) meaning that frustration with a particular service failure is not directly connected to complaint behavior but is likely influenced by one’s attitude toward complaining. Regarding perceptions about complaint behavior under conditions of service failure, the frustration-aggression hypothesis (Berkowitz, 1989) would suggest that as expectations for service delivery are blocked frustration develops around the service failure. Those who have a higher propensity to complain would likely do so when they become frustrated with a service failure.

As noted by Averill (1982), however, mitigating information regarding the service failure can reduce feelings of frustration. Therefore, when consumers have a propensity toward complaining, they will become more frustrated when they do not have mitigating information regarding the service failure (Averill, 1982); or simply put, mitigating information helps reduce frustration. This combination of perceptions also may lead to other behaviors, such as lodging a complaint or displays of aggressive behavior. Rather than focusing on potential behavioral outcomes connected to service failures, this investigation addresses the perceptual elements surrounding complaint formations that contribute to frustration. Therefore, it is proposed that consumers who believe that complaining is an important part of the CSX will indicate a higher need for mitigating information regarding a service failure, as mitigating information ultimately reduces consumers’ frustrations regarding service failures.

Hypothesis 1: Consumers’ propensity to complain is related to higher levels of perceived information inadequacy regarding service failures.

Negative attitude toward complaining. The initial discussion of individuals’ perceptions of the complaint process implies that mitigating information about a service failure will reduce frustration among people most likely to complain about a service failure. Considering the inverse of that relationship, when individuals’ view complaining as a negative activity, the need for mitigating information should be low because information surrounding the service failure is not needed to reduce frustration influenced by a 
natural propensity to complain. When consumers are unlikely to complain concerning a service failure, the elements of attribution normally associated with mitigating information become less important (Averill, 1982). Therefore, it is proposed that consumers who have a negative attitude toward complaining see complaints as less important to the CSX and will indicate a lower need for mitigating information to reduce frustration regarding service failures.

Hypothesis 2: A negative attitude toward complaining is related to lower levels of perceived information inadequacy regarding service failures.

Information inadequacy. It was previously suggested that when service failures occur in the CSX, consumers will choose whether to seek redress through complaints. As consumers evaluate the conditions surrounding the service failure, they will likely seek information regarding the service failure to help process and put closure on the service failure and its surrounding circumstances. Because of mitigating information, the consumer will likely make attributions regarding the service failure and determine through the quality of the information available how serious the service failure is. A higher level of frustration is likely to emerge if consumers experience a high level of uncertainty surrounding the service failure; conversely if a reasonable explanation is offered, consumers are less likely to be frustrated regardless of the service failure, particularly if they view the service failure as unintentional on the part of the service provider (Berkowitz, 1989). Social norms suggest that unintentional service failures occur without harmful intentions, whereas intentional service failures are viewed as personal attacks (Averill, 1982). If insufficient or inaccurate information is provided to the consumer following a service failure, it adds uncertainty to the service experience, limits the consumers' ability to evaluate the cause and effect of the service failure, and likely leads to frustration on the part of the consumer (Fornell \&Westbrook, 1979).

This context-specific proposition is consistent with other organizational frameworks that examine information exchange in organizational settings. In a study of layoff survivors, Casey et al. (1997) found that when workers deal with uncertainty surrounding their job (such as role changes) and experience information deprivation, they tend to engage in information-seeking behaviors to close the information 
gap and reduce uncertainty in their organizational environment. In essence, sufficient levels of information concerning organizational change or adjustments are important to ensure that a smooth transition from the old conditions to the new conditions occurs (Spector, 1978). Similarly in the CSX, when consumers do not receive sufficient information to put closure on a service failure they have attempted to redress, they are likely to experience a heightened sense of uncertainty and become frustrated. This is likely to be exaggerated among consumers when elements of the service process and service recovery remain mainly out of their control (O’Leary-Kelly et al., 1996).

As noted by Day (1984) and Susskind (2002), the product and service characteristics leading up to a complaint will influence the degree to which consumers desire information during a service failure based on the circumstances surrounding the service failure. For example, the degree of mitigating information provided to consumers waiting in queues can reduce negative affect and dissatisfaction (Hui \& Tse, 1996). A common example of a situation requiring a high need for information is an airline flight delay or cancellation. As flights are delayed or cancelled, travelers often report that they do not receive enough information to satisfy their needs regarding the changes to their itinerary and subsequent travel plans (Charles, 1999). When left without sufficient credible information regarding their subsequent travel arrangements and an inherent lack of control over the process, consumers often become frustrated and may display aggressive behavior if the situation is not kept in check (i.e., air rage). Consumer information in the form of factual data about products or services, consumer education, or market regulation have all been identified as information that leads consumers to less frustrating and more satisfying service experiences (Fornell \& Westbrook, 1979). In contrast, perceptions of information inadequacy surrounding service failures can lead to feelings of frustration. Therefore it is proposed that:

Hypothesis 3: Perceived information inadequacy in the CSX regarding service failures is positively related to consumer frustration. 


\section{PILOT STUDY}

The constructs addressed in this investigation did not have questionnaire items associated with them. As a preliminary step, questionnaire items were developed and tested using Hinkin and Tracey’s (1999) ANOVA content validation technique.

\section{Scale Development}

To measure consumer frustration, four questionnaire items were developed. These items were based on the premise that consumer frustration develops because of dissatisfaction with a service experience or service received. The second dimension developed was information inadequacy in the CSX that consisted of five items. The information inadequacy items were developed from the premise that when a dissatisfying service experience occurs, service providers often do not give sufficient information regarding the service failure and remedy. This dimension was developed as a distinct factor from anger or frustration that may develop from service failure or the service received. Last, to measure consumers general views toward complaining about service experiences, 10 questionnaire items developed by Day (1984) were used and defined as belief that complaining to service providers about negative or unsatisfying service experiences is important, necessary, and worthwhile.

Applying the (ANOVA) approach to content adequacy specified by Hinkin \& Tracey (1999), each participant was presented with three sets of the 19 questions mentioned earlier, each with a definition on the top of the page. The three specific definitions given to the respondents were the following:

- Definition \#1: Consumer frustration is defined as a feeling of anger or frustration that develops due to dissatisfaction with a service experience or the level of service received.

- Definition \#2: Information inadequacy in service experiences is defined as the belief that when a negative or unsatisfying service experience occurs, service providers often do not give sufficient or accurate information to the consumer about the service failure or the remedy. This is separate from frustration or anger that may result from the service failure. 
- Definition \#3: Customers' attitudes toward the act of complaining is defined as the belief that complaining to service providers about a negative or unsatisfying service experience is important, necessary, and worthwhile.

With these three definitions, the participants were asked to rate each of the 19 items three times in comparison to the three definitions provided. The ratings were conducted using a 5-item Likert-type metric indicating the extent to which the participants believed each item matched the definition presented to them (highly agree, agree, neutral, disagree, and highly disagree). Two versions of the questionnaire were presented to the participants with the items and definitions presented in a different sequence to mitigate concerns over item-definition ordering effects. Six of the complaint items and one consumer frustration item were asked in reverse form (i.e., agreement with the item represents a negative response). These seven items were recoded for alignment with the items presented in positive form.

\section{Participants and Procedure}

For this study, 111 business college freshman enrolled in a course in food and beverage management were surveyed. The participants were approximately 52\% men $(\mathrm{n}=58)$ and 48\%women $(\mathrm{n}=$ 53), between the ages of 17 and $38(M=18.57, S D=.78$, median $=18)$.

Step 1: Exploratory factor analysis. Principal components analysis with varimax rotation was applied to the data using SPSS Version 10.0. This combination of factor analytic techniques was selected to maximize the amount of variance explained by the variables through the formation of uncorrelated linear combinations of the variables (Norusis, 1993). Factor and item retention were based on (a) an examination of a scree plot to determine the distinct breaks in the plots separating the tenable factors from the untenable, (b) items not displaying cross loadings with other factors greater than .40, and (c) items exhibiting principal factor loadings greater than .50. Based on these three criteria, the emergent factor structure was examined for theoretical and conceptual clarity.

The initial principal components analyses with varimax rotation yielded a 4- factor solution, with the scree plot identifying four breaks in the plot of the eigenvalues greater than 1.0. The first break identified the information inadequacy dimension and explained $19.10 \%$ of the variance, the second break 
identified a portion of the complaint attitude dimension and explained $17.71 \%$ of the variance, the third break identified the other portion of the complaint attitude dimension and explained $11.56 \%$ of the variance, and the fourth break identified the consumer frustration dimension and explained $11.04 \%$ of the variance for a total of $59.21 \%$ for the four identified factors. The information inadequacy dimension showed no deviation from the proposed structure, suggesting that all five items be retained in the final solution. Item 3 from the consumer frustration dimension showed a principal factor loading less than .50 suggesting that the consumer frustration dimension be represented by the remaining three items. The first emergent complaint attitude factor consisted of Item 1, Item 2, Item 3, and Item 8; the second emergent complaint attitude factor consisted of Item 4, Item 5, Item 6, and Item 7. Item 9 did not show a principal factor loading greater than .40 on either of the emergent complaint factors, and Item 10 cross-loaded with both of the emergent complaint factors. Therefore, Item 9 and Item 10 were excluded from consideration in the model based on the factor analyses. The remaining 16 items created a final 4-factor solution explaining $66.30 \%$ of the variance and resulted in two 4-item representations of attitudes toward complaining, a 3-item representation of consumer frustration, and a 5-item representation of information inadequacy.

The exploratory factor analyses identified a set of items that sufficiently represented each hypothesized construct. These initial analyses suggested that the complaint measure as proposed by Day (1984) be represented by two factors. All of the original questionnaire items are presented in Table 1 along with the initial factor loadings greater than .30 .

Step 2: Content validation. To complete the item validity assessments, the mean rating scores for each item on the Consumer Frustration, Information Inadequacy, and Complaint Attitude scales were calculated. Three scores were computed for the consumer frustration items, one for the a priori matching definition, and two for each of the alternative definitions. Three scores also were computed for the five information inadequacy items and the 10 complaint attitude items in the same manner. Each item's set of three ratings was then compared using ANOVA (see Table 2). Results of the ANOVAs only differed 
slightly from those of the exploratory factor analysis reported earlier, and only one of the two emergent complaint factors was consistent with the definition provided.

Perceptions of consumer frustration. The mean ratings for Item 3 did not differ across the three dimensions, indicating that the respondents did not see this item as being uniquely associated with the construct definition of consumer frustration they were provided. This finding is consistent with the results of the exploratory factor analyses reported previously and suggests that the three remaining items be retained in the final factor solution to represent the perceptions of Consumer Rage factor.

Perceptions of information inadequacy. All five of the information inadequacy items were rated higher on their a priori dimension compared to the alternative dimensions of consumer frustration and attitudes toward complaining. Again, this finding is consistent with the factor analyses reported previously and suggests that all five items be retained in the final solution to represent the dimension of information inadequacy in service experiences.

Attitude toward the act of complaining. Of the 10 original complaint attitude items from the two emergent factors, only four items were rated significantly higher on their a priori dimension compared to the alternative dimensions. These findings highlight some issues needing further clarification. Because Day's (1984) original scale did not specify two factors, only one a priori definition was created to be used with the content validity assessment. This, by design, limited the potential to examine both emergent complaint factors fully using Hinkin and Tracey’s (1999) content validation technique. It is appropriate, however, to further consider Factor 2 given the strong relationships that were uncovered through the factor analysis. As presented, the two emergent complaint factors seem to consist of two refined dimensions of attitudes toward the complaint process: (a) propensity to complain (four items) and (b) perceptions of complaining as a negative behavior (four items).

Propensity to complain. The four items that passed the content validation tests-Item 4, Item 5, Item 6, and Item 7—addressed the consumers' perceived motivation to complain when dissatisfied based on the efforts, obligations, and personal outcomes related to lodging a complaint. 
Perceptions of complaining as a negative behavior. Although the second 4- item complaint attitude subfactor that emerged from the factor analyses did not pass the content validation tests based on the definition provided-Item 1, Item 2, Item 3, and Item 8-a closer look at the wording of these items indicates that the items tap into the perceived negative affect and outcomes associated with complaining when dissatisfied. Clearly there is some merit to Factor 2 given that all the items regarding negative perceptions of complaining grouped together in the factor analyses. To fully validate these items, an additional matching definition would need to be created and included in a subsequent content validation study; however, given the four item's factor structure and acceptable reliability coefficient $(\alpha=.86)$ they warranted further consideration in the study.

Complaint Item 10 was rated higher on its a priori dimension compared to the alternative dimensions; however, as noted earlier, it did not meet the criteria for inclusion in the factor analysis. Item 10 identified a personality attribute that is likely to be associated with chronic complainers and was the only item that made a specific reference to people personally known by the respondent. The fact that this item cross-loaded with both of the emergent complaint dimensions suggests that personality traits are likely important influences of complaint behavior and might add additional explanatory power to models examining perceptions of complaint behavior. Last, complaint Item 9 did not pass either the factor analysis stage or the content validation stage. Item 9 addressed business' violations of consumer rights in service experiences that was too broad an item to align with attitudes toward the complaint process as presented. These findings suggest that Day's (1984) 10 original items be represented as two 4-item dimensions of attitudes toward complaining: one based on an propensity to complain when dissatisfied and one based on negative perceptions of complaining behavior.

When combining the results of the blind factor analysis and the item-mean comparisons, the results of the pilot study suggest that three items did not meet the criteria for inclusion in the final scales. The analyses led to the same conclusion concerning the content and structure of the proposed scales. However, it was not possible to fully evaluate the second emergent complaint factor, as an a priori matching definition was not created and used in the data collection and analyses. The two-stage approach to content validation 
used here provided an assessment of the items' interrelationships and suggested that (a) a three-item representation of consumer frustration be retained from the four original items $(\alpha=.72)$, (b) a 5-item representation of information inadequacy regarding service experiences be retained from the five original items $(\alpha=.85)$ and (c) a 4 -item representation of propensity to complaining $(\alpha=.72)$, and a 4-item representation of negative perceptions of complaining $(\alpha=.86)$ be retained.

\section{METHOD}

\section{Participants and Procedure}

Two-hundred-and-thirty mall patrons were solicited while shopping. Mall patrons were selected because they were in the process of shopping and were currently engaged in some form of retail transaction. Securing respondents from this environment offered a primer for them to respond to questions related to their perceptions of service experiences. The data were collected from a table setup in front of the mall's food court over a 2-month period capturing a mix of the mall's operating times on weekdays and weekends across the morning, afternoon, and evening hours. Participants were asked to fill out a questionnaire in exchange for a lottery ticket with a face value of $\$ 1.00$. Involvement in the study was voluntary, and each participant was assured confidentiality in their responses. Due to state regulations regarding the lottery, each participant was older than the age of 18.

The participants were $41 \%$ men $(n=4)$ and 59\%women $(n=136)$, between the ages of 18 and 73 years $(\mathrm{M}=31.77, \mathrm{SD}=14.58$, median $=24)$. Of the participants, 76 reported having a 4-year college or postgraduate education, 105 reported attending some college or being currently enrolled in college, 7 reported having a technical degree, 40 reported having a high school degree, and 2 did not complete high school. The participants reported varied household income levels with 72 respondents reporting income less than \$20,000 per year, 96 respondents reporting between $\$ 20,000$ and \$50,000 per year, 33 respondents reporting between $\$ 50,000$ and $\$ 80,000$ per year, and one participant reported income greater than $\$ 80,000$. Five participants did not respond to the question. 


\section{Measurement}

The pilot study validated 16 items from four constructs to assess the model of consumer frustration as proposed previously. Participants indicated their level of agreement on a 5-item Likert-type metric assessing perceptions of: consumer frustration (three items), information inadequacy (five items), one’s propensity to complain (four items), and negative perception of complaining (four items).

\section{Confirmatory Factor Analysis}

Confirmatory factor analysis was applied to test the unidimensionality of the scales (Hunter \& Gerbing, 1982). Confirmatory factor analysis was employed with LISREL 8.12a (Jöreskog \& Sörbom, 1993) using a covariance matrix as input. Three goodness-of-fit statistics were reported for the confirmatory factor analysis: (a) adjusted goodness of fit index (AGFI), (b) nonnormed fit index (NNFI), and (c) standardized root mean squared residual (RMR). A good fit of a model to the data using the AGFI and NNFI indicators is characterized by values exceeding .90 (Bentler \& Bonnett, 1980; Medsker, Williams, \& Holahan, 1994). An RMR indicates a good fitting model when the residuals comparing the fitted and observed covariance matrix are small (i.e., less than .05) (Byrne, 1998).

The factor analyses yielded four internally consistent factors as hypothesized (AGFI $=.91$, NNFI $=.93$, and $\mathrm{RMR}=.03$ ), indicating that the four final scales met the requirements of internal consistency and parallelism (Hunter \& Gerbing, 1982). The item-level correlations are reported in Table 3, and the scale-level descriptive statistics, reliabilities, and correlations are presented in Table 4.

\section{Control Variables}

To determine if the participants sociodemographic characteristics (sex, income, education, and age) were associated with perceptions of consumer frustration, information inadequacy, propensity to complain, and negative attitude toward complaining, several statistical tests were conducted. ${ }^{1}$ Based on

\footnotetext{
1 The $t$ tests examining the effect of sex in the model with the perceptions of frustration, propensity to complain, and negative attitude toward complaining, $\mathrm{t}(228)=1.12, \mathrm{p}=.27, \mathrm{t}(228)=.65, \mathrm{p}=.52$, and $\mathrm{t}(228)=$ $1.27, \mathrm{p}=.21$, respectively, were not significant; however as noted earlier, the effect of sex with information inadequacy was significant, $\mathrm{t}(228)=2.49, \mathrm{p}=.01$. ANOVA was used to examine the influence of education and income in the model and revealed no significant differences regarding the respondents educational level in relationship to consumer frustration, $\mathrm{F}(3,224)=.56, \mathrm{p}=.64, \eta 2=.01$; information inadequacy, $\mathrm{F}(3,224)=$
} 
the analyses reported in Note 1, only the effect of respondent's sex on information inadequacy proved to be significant, indicating that the female respondents reported a greater level of perceived information inadequacy regarding service failures compared to their male counterparts $(M=4.21$ and $M=3.99$, respectively). To account for this effect in the subsequent path analyses, a path was added to the model showing sex as an antecedent of information inadequacy as a dummy-coded variable (male $=0$ and female $=1)$.

\section{Path Analysis}

Following tests of confirmatory factor analysis and an examination of the control variables, the hypothesized model was tested with LISREL Version 8.12a using a covariance matrix as input (Jöreskog \& Sörbom, 1993). By default, the error terms were permitted to correlate, and no other relationships other than those specified in the path diagram were permitted to correlate in the structural analyses. To compensate for measurement error in the scale values within the path model, the paths from the latent variables to the indicators were set to the square root of the scale reliability. In addition, the error variance was set to equal the variance of the scale multiplied by one minus the reliability. These procedures fix the proportion-of-error variance assigned to each factor based on the reported scale reliabilities and the relevant variance associated with each factor (Hayduk, 1987). The same cutoff criteria applied to the factor analyses were used. In this case, negative attitude toward complaining and propensity to complain were treated as exogenous variables in the model. Moreover, sex was included in the model as an antecedent of information inadequacy. Information inadequacy and consumer frustration were treated as

\footnotetext{
$1.38, \mathrm{p}=.33, \eta 2=.02$; propensity to complain, $\mathrm{F}(3,224)=.24, \mathrm{p}=.87, \eta 2<.01$; or negative attitude toward complaining, $\mathrm{F}(3,224)=1.28, \mathrm{p}=.29, \eta 2=.03$. In addition, no significant effects were revealed from the respondents' reported income level in relationship to perceptions of consumer frustration, $\mathrm{F}(2,222)=.41, \mathrm{p}=$ $.66, \eta 2=.01$; information inadequacy, $\mathrm{F}(2,222)=.17, \mathrm{p}=.84, \eta 2<.01$ : propensity to complain, $\mathrm{F}(2,222)=$ $.37, \mathrm{p}=.69, \eta 2=.02$; or negative attitude toward complaining, $\mathrm{F}(2,222)=.19, \mathrm{p}=.83, \eta 2=.01$. The one respondent who reported an income greater than $\$ 80,000$ and the two respondents who reported not having high school diplomas were excluded from these analyses to avoid problems with interpreting the findings from unbalanced cells. Last, the regression analyses revealed no significant effects of the respondents' age for perceptions of consumer frustration, $\mathrm{R}=.005, \mathrm{p}=.94, \mathrm{R} 2=.001$; information inadequacy, $\mathrm{R}=.05, \mathrm{p}=.49$, R2 $=.002$; propensity to complain, $\mathrm{R}=.12, \mathrm{p}=.07, \mathrm{R} 2=.02$ ); or negative attitude toward complaining, $\beta=.02, \mathrm{p}$ $=.80, \mathrm{R} 2=.001)$.
} 
the endogenous variables in the model, with information inadequacy presented as a mediator of the relationships between negative attitude toward complaining and consumer frustration, propensity to complain and consumer frustration, and sex and consumer frustration.

\section{RESULTS}

\section{Path Analysis}

The test of the hypothesized path model between respondent sex, negative attitude toward complaining, propensity to complain, information deficiency, and consumer frustration was subsequently tested using the final factors resulting from the confirmatory factor analyses (see Figure 2). The model as specified fit the data quite well $(\mathrm{AGFI}=.98, \mathrm{NNFI}=.98, \mathrm{RMR}=.01, \chi 2[3]=.80, \mathrm{p}=.85)$. The path coefficient from respondent sex to information inadequacy was significant $(\beta=.17, \mathrm{p}<.05)$. The path coefficient from propensity to complain to information Inadequacy was significant $(\beta=.31, \mathrm{p}<.001)$ providing support for Hypothesis 1. Hypothesis 2 was not supported as the path coefficient from negative attitude toward complaining was not significant $(\beta=.10)$; and the path coefficient from information inadequacy to consumer frustration was significant $(\beta=.59, \mathrm{p}<.001)$ providing support for Hypothesis 3. The model explained a total of 51\%of the variance, with sex, negative attitude toward complaining, and propensity to complain explaining $16 \%$ of the incremental variance in information inadequacy, and information inadequacy explaining 35\% of the incremental variance in consumer frustration.

\section{Tests of Rival Models}

To ensure that the model presented as Figure 2 represented the best fit to the data, two alternative models were tested. The first alternative model treated sex as an antecedent to information inadequacy. Information inadequacy was then connected to negative attitude toward complaining and propensity to complain. Last, negative attitude toward complaining and propensity to complain were connected to perceptions of consumer frustration. This first alternative model did not fit the data well (AGFI = .74, $\mathrm{NNFI}=.41, \mathrm{RMR}=.07)$, suggesting that the hypothesized model offers a better representation of the data. The second alternative model was tested using multiple regression. Consumer frustration was treated as 
the sole dependent variable in the model, and negative attitude toward complaining, propensity to complain, and information inadequacy were treated as independent variables in the model. Sex was not included in these analyses because the control analyses showed no effect of sex on consumer frustration. Although the analysis revealed a significant effect for the equation, $F(3,226)=24.38, \mathrm{p}<.001$, R2 $=.24$, an examination of the regression coefficients revealed that information inadequacy was the sole significant contributor to the model, $(\beta=.48, \mathrm{t}[1]=8.01, \mathrm{p}<.001)$. Negative attitude toward complaining and propensity to complain produced nonsignificant effects in the model $(\beta=.06, t[1]=1.06, \mathrm{p}=.29$ and $\beta=.05, \mathrm{t}[1]=.88, \mathrm{p}=.38$, respectively). The tests of these two alternative models support the findings reported earlier indicating that Figure 2, as presented, best models the data.

\section{DISCUSSION}

This investigation applied previous research examining consumers’ compliant attitudes, information deficiency, and consumer aggression to develop and test a model of consumer frustration. This investigation extends the work of Day (1984), Fornell and Westbrook (1979), and Bennett (1997) on consumer complaint processes to the frustration-aggression hypothesis (Berkowitz, 1989) with a specific application examining the CSX.

Several notable findings emerged from this investigation. First, building on the results from the pilot test, measures to assess consumers frustration and the relative influences were evaluated and confirmed with a sample of retail consumers. As presented, the measure of consumer frustration taps into consumers' levels of frustration that are likely to emerge from dissatisfying service experiences. Having a general understanding of and the ability to directly measure consumers' tendencies for frustration in the CSX can be used as a tool to train and develop customer service employees to spot potential concerns among customers. Likewise, the measure of information inadequacy shows that information is an important factor in consumer-based decision making and behavior in the CSX and offers researchers a means to assess the role that information plays regarding service failures and ensuing frustration in the CSX. In addition, the complaint items (Day, 1984) as classified assess consumers' perceptions of the 
complaint process, including their propensity to complain when a service failure occurs and how they view the act of complaining as a consumer behavior.

Next, it was demonstrated that women reported a higher level of information inadequacy regarding service failures they experience. This finding suggests that service providers might offer less service-related information to their female customers when a service failure occurs compared to their male customers. There is mixed support for an overarching sociodemographic framework to apply to this line of research. For instance, Garrett, Meyers, and West (1997) found no differences among WOM behavior between male and female respondents regarding a dissatisfying service experience. Conversely, Liefield, Edgecombe, and Wolfe (1975) and Warland, Herman, and Willits (1975) reported that male respondents complained more about service failures than female respondents, however female respondents reported a higher level of dissatisfaction with the service failures despite the fact that they engaged in fewer voice-based responses than their male counterparts. These differences in empirical reports suggest that sociodemographic effects should continue to be controlled for in analyses of consumer behavior (Pol, 1991) because it is likely that men and women may engage in different shopping behaviors and have different needs in the CSX regarding service failures.

In this investigation, consumers’ attitudes toward complaining were connected to information inadequacy, and perceptions of information inadequacy were connected to consumer frustration. The noted relationship between consumers propensity to complain and information inadequacy suggests that those who have a higher propensity to complain also have a higher need for information from service providers when they experience service failures in the CSX. The inverse of this relationship, represented by the negative attitude complaint dimension, was not significant in the model although the relationship emerged in the anticipated direction. This relationship suggests that consumers who report a negative attitude toward complaining do not consistently report a low need for information regarding service failures as proposed. It could be that these consumers are nonassertive or conflict avoidant and prefer to not directly deal with service failures in any way (Fornell \& Westbrook, 1979). The noted relationship between information inadequacy and consumer frustration suggests that not receiving sufficient 
information in the CSX when a service failure occurs leads to frustration and can be the trigger for an act of aggression to occur.

\section{Managerial Implications}

This study was conducted among a group of retail consumers while shopping and highlights several implications for managers of service-based organizations. First, the nature of questions asked was very general and did not apply to any particular type of service organization. What can be gained from this general application is that consumers view the complaint process as important. The data show that consumers will not only complain to remedy their own situation but also that complaining appears to be therapeutic and helps restore equity to them in the CSX. This suggests that managers need to pay particular attention to how complaints are handled to ensure that the sense of equity that the customer is seeking is appropriately regained. In other words, operators should make it easy for their customers to lodge their complaints and should attempt to seek feedback from their customers at regular intervals during service episodes. This is particularly important for hospitality managers where service episodes can range from a few minutes in a quick-service restaurant to several weeks in a resort community.

There was also a strong relationship between consumers propensity to complain and their need for information regarding service failures. The data show that a lack of forthright and timely information regarding a service failure is likely to lead to frustration on the part of the consumer. Managers should be careful to ensure that customers receive the most timely and accurate information regarding service failures. If you can recall a time while dining in a restaurant and receiving slow service where the servers response is "The kitchen is backed-up tonight," or an airline flight delay where the counter attendant says “They are refueling the plane.” These statements are good for consumers as long as they are truthful and accurate, because any further delays or problems that may arise will show that they were not truthful with the consumer, and that dynamic is likely to lead to dissatisfaction and, ultimately, frustration on the part of the consumer. Operators of service-based businesses need to train their customer contact employees to provide guests with accurate and timely accounts of the causes behind service failures to help smooth out 
the recovery process and reduce the chances that customers will experience frustration as a result (directly or indirectly) of a service failure.

When service employees and their managers openly communicate among themselves and their customers, everyone in the CSX will gain a better understanding of the service process and how and when to improve it.

In most cases, better informed customers can make better decisions about how to proceed following service failures (Hui \& Tse, 1996). Building on the previous restaurant and airline examples, if service is truly slow because the kitchen is in the weeds (a temporary state of chaos), if a customer is time sensitive (e.g., has to catch a show, return to work, catch a flight, etc.) a slow food production process may require a different action compared to a server being forgetful or inattentive. Likewise, with the airline example, if the plane is truly refueling, then the delay should be relatively short. However, if the plane is short a crew member or is grounded for mechanical repairs, knowing those facts about the service episode offers the consumer options on how to proceed, such as waiting, finding alternative flight arrangements, or finding alternative ground transportation. Last, managers of service-based organizations need to recognize that most people just want the facts and might be frustrated but will likely cool down when they are given options on how to proceed with the service recovery process.

\section{Future Research}

Given the results of this investigation, it seems that developing a more complete model of consumers affect and behavior in the CSX would be beneficial. Given that the variables in Figure 2 accounted for $51 \%$ of the variance in the model, it is likely that other influences in the CSX can also be attributed to consumer frustration in the CSX. Additional research can address this in several ways. First, the assumption behind the model of consumer frustration presented here is that dissatisfaction with service-related processes emerges from or evolves in the CSX and creates specific frustrations when expectancies are blocked. This assumption does not account for additional state-based influences of frustration external to the service episode, such as consumers time sensitivity, work-family role conflict, or mood. For example, being short of time, having too many conflicting obligations, or merely being in a 
bad mood may lead to frustrations when dealing with service failure; however, these frustrations may not occur across episodes. Trait-based influences, on the other hand, such as personality or disposition, may also be important influences on frustration. If consumers are generally disagreeable or neurotic, a service failure may consistently lead to frustration or anger when it occurs. Additional studies should include an assessment of consumers' trait- and state-based problems to help parse out the additional factors that affect consumers' reactions to service failures.

Second, consumers' reactions to a service failure in the CSX may also be influenced by structural elements of the service exchange. Issues such as whether the service failure is viewed as a personal affront, whether monetary issues are important to the exchange, whether the consumer has an existing relationship with the organization or service provider, or the severity of the service failure may all be important to consumers' complaint behavior and reactions. For example, consumers may be less reactive if they are more familiar or comfortable with the context of the service environment, or if they perceive that less is at stake. In a study of restaurant customers by Susskind (2002), it was shown that customers' reactions to service failures varied depending on the type of the service failure, the degree of correction offered and whether the experience with the failure was viewed as positive or negative. Gauging consumers' context-specific reactions to service failure leading to frustration is an important next step in this line of research.

Last, although consumer frustration is an affective response, consumer aggression or rage is a behavioral response. Future work should identify and measure specific behavioral outcomes linked to consumer frustration, such as aggression or rage, repatronage intentions, and WOM communication.

\section{Limitations}

This investigation created a preliminary step identifying how consumers' reactions to service failures can lead to frustration in the CSX. That being said, this line of research will benefit greatly by moving beyond cross-sectional, monomethod designs. Being able to examine consumers’ reactions to dissatisfying service experiences over time and making connections from consumers to service providers should allow researchers to begin to make causal attributions, not only for cognitive schemas regarding 
service experiences but also for specific behaviors and outcomes emerging from the CSX. Through additional measurements — such as the critical incident technique and performance-based data from employees, customers, and service organizations—researchers can begin to capture event-specific perceptions of service experiences and match responses from consumers, employees, and service organizations to offer a cross-level representation of consumer frustration and how it is related to the delivery and consumption of service experiences.

\section{Conclusion}

For years researchers have tried to better understand the human side of consumerism and describe the elements that have the greatest influence on consumer satisfaction and organizational success. In their research, Fornell and Westbrook (1979) noted a distinction between aggressive and assertive consumer behavior, suggesting that the later is a desirable, learned characteristic that allows consumers to actively meet their expectations for service experiences, whereas the former suggests taking assertiveness inappropriately too far in the CSX. Conversely, Bennett (1997) and Feshbach (1984) suggested that when angry consumers blow off steam the process can be helpful and therapeutic for them. What is not considered, however, is the negative impact that this catharsis may have on those who are party to the outburst (i.e., other customers and service providers). If an organization and its agents regularly and sincerely take unconditional responsibility for their service failures to actively reduce consumer frustration, it is possible to reduce the negative emotional reactions of consumers when they are dissatisfied. This approach is likely to minimize the frequency and the severity of consumer frustration and aggression in service-based organizations. 


\section{NOTES}

1. The t tests examining the effect of sex in the model with the perceptions of frustration, propensity to complain, and negative attitude toward complaining, $\mathrm{t}(228)=1.12, \mathrm{p}=.27, \mathrm{t}(228)=.65, \mathrm{p}=$ .52 , and $t(228)=1.27, \mathrm{p}=.21$, respectively, were not significant; however as noted earlier, the effect of sex with information inadequacy was significant, $\mathrm{t}(228)=2.49, \mathrm{p}=.01$. ANOVA was used to examine the influence of education and income in the model and revealed no significant differences regarding the respondents educational level in relationship to consumer frustration, $\mathrm{F}(3,224)=.56, \mathrm{p}=.64, \eta 2=.01 ;$ information inadequacy, $\mathrm{F}(3,224)=1.38, \mathrm{p}=.33, \eta 2=.02$; propensity to complain, $\mathrm{F}(3,224)=.24, \mathrm{p}=.87, \eta 2<.01$; or negative attitude toward complaining, $\mathrm{F}(3,224)=1.28, \mathrm{p}=.29, \eta 2=.03$. In addition, no significant effects were revealed from the respondents' reported income level in relationship to perceptions of consumer frustration, $\mathrm{F}(2,222)=.41, \mathrm{p}=.66, \eta 2=.01$; information inadequacy, $\mathrm{F}(2,222)=.17, \mathrm{p}=.84$, $\eta 2<.01$ : propensity to complain, $\mathrm{F}(2,222)=.37, \mathrm{p}=.69, \eta 2=.02$; or negative attitude toward complaining, $\mathrm{F}(2,222)=.19, \mathrm{p}=.83, \eta 2=.01$. The one respondent who reported an income greater than $\$ 80,000$ and the two respondents who reported not having high school diplomas were excluded from these analyses to avoid problems with interpreting the findings from unbalanced cells. Last, the regression analyses revealed no significant effects of the respondents' age for perceptions of consumer frustration, $\mathrm{R}=.005, \mathrm{p}=.94, \mathrm{R} 2=.001$; information inadequacy, $\mathrm{R}=$ $.05, \mathrm{p}=.49, \mathrm{R} 2=.002$; propensity to complain, $\mathrm{R}=.12, \mathrm{p}=.07, \mathrm{R} 2=.02$ ); or negative attitude toward complaining, $\beta=.02, \mathrm{p}=.80, \mathrm{R} 2=.001)$. 


\section{REFERENCES}

Anderson, E.W., Fornell, C., \& Rust, R.T. (1997). Customer satisfaction, productivity, and profitability: Differences between goods and services. Marketing Science, 16(2), 129- 145.

Averill, J. R. (1982). Anger and aggression: An essay on emotion. New York: Springer- Verlag.

Bandura, A. (1973). Aggression: A social learning analysis. Englewood Cliffs, NJ: Prentice Hall.

Bennett, R. (1997). Anger, catharsis, and purchasing behavior following aggressive customer complaints. Journal of Consumer Marketing, 14(2), 156-172.

Bentler, P. M. ,\& Bonnett, D. G. (1980). Significance tests and goodness of fit in the analysis of covariance structures. Psychological Bulletin, 88(3), 588-606.

Berkowitz, L. (1989). Frustration-aggression hypothesis: Examination and reformulation. Psychological Bulletin, 106(1), 59-73.

Byrne, B. M. (1998). Structural equation modeling with LISREL, PRELIS, and SIMPLIS: Basic concepts applications, and programming. Mahwah, NJ: Lawrence Erlbaum.

Casey, M., Miller,V. D., \& Johnson, J. R. (1997). Survivors information seeking following a reduction in workforce. Communication Research, 24(6), 755-781.

Charles, C. L. (1999). Why is everyone so cranky? New York: Hyperion.

Collie, T. A., Sparks, B., \& Bradley, G. (2000). Investigating interactional justice: A study of the fair process effect within a hospitality failure context. Journal of Hospitality \& Tourism Research, 24(4), 448472.

Davidow, M. (2000). The bottom line impact of organizational responses to customer complaints. Journal of Hospitality \& Tourism Research, 24(4), 473-490.

Day, R. L. (1984). Modeling choices among alternative responses to dissatisfaction. Advances in Consumer Research, 11, 496-499.

Day, R. L., \& Ash, S. B. (1979). Consumer responses to dissatisfaction with durable products. Advances in Consumer Research, 6, 438-444. 
Day, R. L., \& Bodur, M. (1978). Consumer response to dissatisfaction with services and intangibles. Advances in Consumer Research, 5, 263-272.

Dollard, J., Doob, L., Miller, N., Mowrer, O., \& Sears, R. (1939). Frustration and aggression. New Haven, CT: Yale University Press.

Feshbach, S. (1984). The catharsis hypothesis, aggressive drive, and the reduction of aggression. Aggressive Behavior, 10(1), 91-101.

Fornell, C., \& Westbrook, R. A. (1979). An exploratory study of assertiveness, aggressiveness, and consumer complaining behavior. Advances in Consumer Research, 6, 105-110.

Garrett, D. E., Meyers, R. A., \& West, L. (1997). Sex differences and consumer complaints: Do men and women communicate differently when they complain to service representatives. Journal of Consumer, Satisfaction, Dissatisfaction, and Complaining Behavior, 10, 116-130.

Harris, M. B. (1974). Mediators between frustration and aggression in a field experiment. Journal of Experimental Social Psychology, 10(5), 561-571.

Hayduk, L. A. (1987). Structural equation modeling with LISREL: Essentials and advances. Baltimore: Johns Hopkins University Press.

Hinkin, T. R., \& Tracey, J. B. (1999). An analysis of variance approach to content validation. Organizational Research Methods, 2(2), 175-186.

Hui, M. K., \& Tse, D. K. (1996). What to tell customers in waits of different lengths: An integrative model of service evaluation. Journal of Marketing, 60(2), 81-90.

Hunter, J. E., \& Gerbing, D.W. (1982). Unidimensional measurement, second order factor analysis, and causal models. Research in Organizational Behavior, 4, 267-320.

Jöreskog, K. G., \& Sörbom, D. (1993). LISREL for Windows 8.12a. Chicago: Scientific Software International, Inc.

Liefield, J. T., Edgecombe, F.H.C., \& Wolfe, L. (1975). Demographic characteristics of Canadian consumer complainers. Journal of Consumer Affairs, 9(1), 73-80. 
Medsker, G. J., Williams, L. J., \& Holahan, P. J. (1994). A review of current practices for evaluating causal models in organizational behavior and human resources management research. Journal of Management, 20(3), 439-464.

McCollough, M. A. (2000). The effect of perceived justice and attributions regarding service failure and recovery on post-recovery customer satisfaction and service quality attitudes. Journal of Hospitality \& Tourism Research, 24(4), 423-447.

Mount, D. J., \& Mattila, A. (2000). The final opportunity: The effectiveness of a customer relations call center in recovering hotel guests. Journal of Hospitality \& Tourism Research, 24(4), 518-525.

Neuman, J. H., \& Baron, R. A. (1998).Workplace violence and workplace aggression: Evidence concerning specific forms, potential causes, and preferred target. Journal of Management, 24(3), 391-419.

Norusis, M. J. (1993). SPSS for Windows base system users guide. Chicago: SPSS, Inc.

O’Leary-Kelly, A. M., Griffin, R. W., \& Glew, D. J. (1996). Organization-motivated aggression: A research framework. Academy of Management Review, 21(1), 225-253.

Peterson, K. S. (2000, July 18). Why is everyone so short-tempered? USA Today, p. 1A.

Pol, L. G. (1991). Demographic contributions to marketing: An assessment. Journal of the Academy of Marketing Science, 19(1), 53-59.

Scanian, L., \& McPhail, J. (2000). Forming service relationships with hotel business travelers: The critical attributes to improve retention. Journal of Hospitality \& Tourism Research, 24(4), 491513.

Singh, J. (1988). Consumer complaint intentions and behavior: Definitional and taxonomical issues. Journal of Marketing, 52(1), 93-107.

Singh, J., \& Wilkes, R. E. (1996). When consumers complain: A path analysis of the key antecedents of consumer complaint response estimates. Journal of the Academy of Marketing Science, 24(4), 350-365. 
Spector, P. E. (1978). Organizational frustration: A model and review of the literature. Personnel Psychology, 31(4), 815-829.

Susskind, A. M. (2000). Efficacy and outcome expectations related to customer complaints about service experiences. Communication Research, 27(3), 353-378.

Susskind, A. M. (2002). I told you so! Restaurant consumers word-of-mouth communication. Cornell Hotel and Restaurant Administration Quarterly, 43(2), 75-85.

Susskind, A. M., Borchgrevink, C. P., Brymer, R. A., \& Kacmar, K.M. (2000). Customer service behavior and attitudes among hotel managers: A look at perceived support functions, standards for service, and service process outcomes. Journal of Hospitality \& Tourism Research, 24(3), 374-398.

Susskind, A. M., Borchgrevink, C. P., Kacmar, K. M., \& Brymer, R. A. (2000). Customer service employees' behavioral intentions and attitudes: An examination of construct validity and a path model. International Journal of Hospitality Management, 19(1), 53-77.

Tedeschi, J. T., \& Felson, R. B. (1994). Violence, aggression, and coercive actions. Washington, DC: American Psychological Association.

Warland, R. H., Herman, R. O., \& Willits, J. (1975). Dissatisfied consumers: Who gets upset and who takes action. Journal of Consumer Affairs, 9(2), 148-163. 


\section{Table 1. Item-Factor Loadings from the Factor Analysis in Study One ${ }^{a}$}

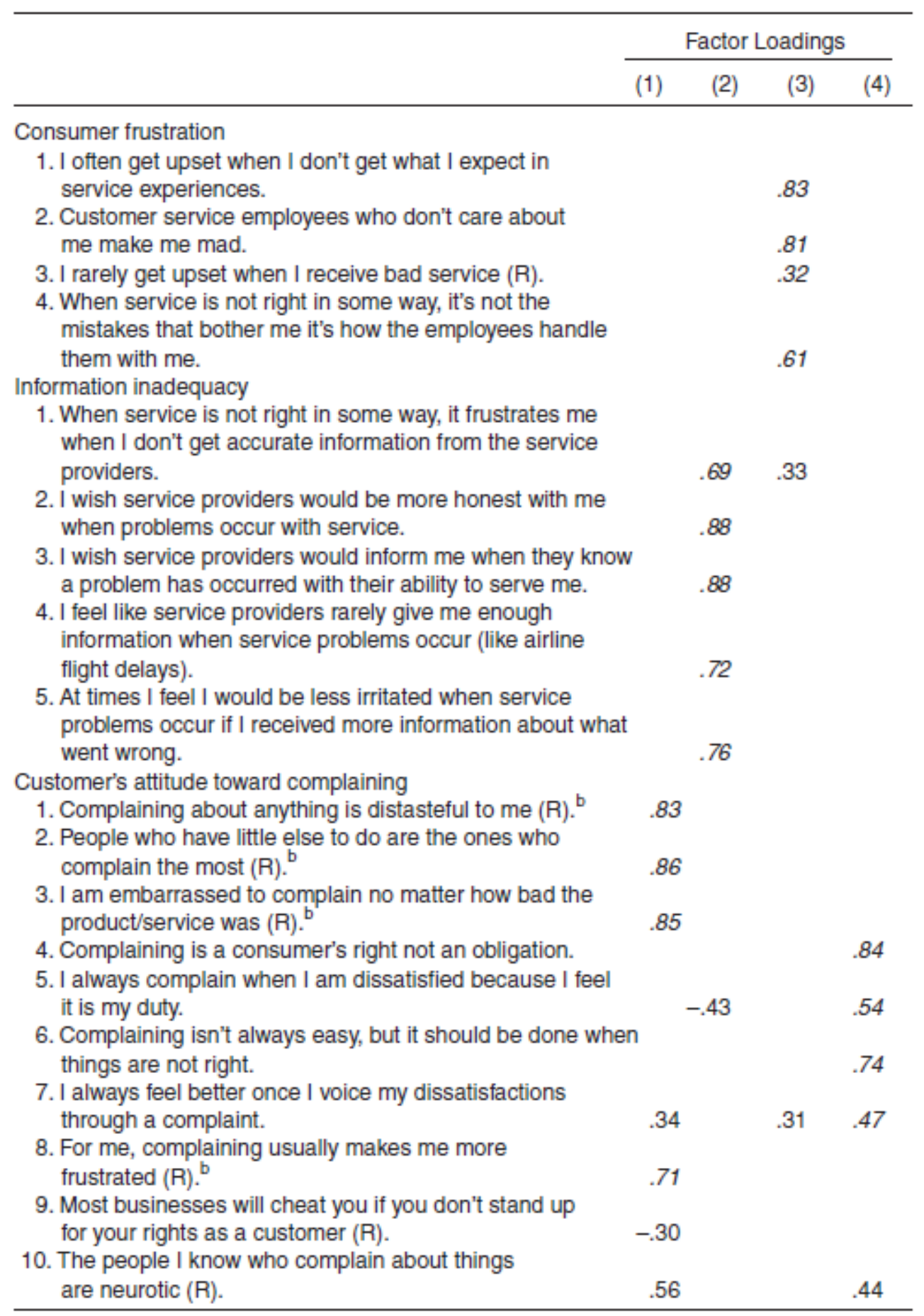

a. Only factor loadings greater than .30 are reported.

b. Denotes an item from the emergent complaint dimension labeled as negative attitude toward complaining.

Note: $(R)$ denotes an item asked in reverse form where a low response represents a high level of affect and vice versa.

Items presented in italics are the ones that passed the acceptance criteria. 
Table 2. Mean Ratings for the Content Validation Assessment ${ }^{\mathrm{a}}$

\begin{tabular}{|c|c|c|c|}
\hline Scale Item & $\begin{array}{c}\text { Consumer } \\
\text { Rage }\end{array}$ & $\begin{array}{l}\text { Information } \\
\text { Inadequacy }\end{array}$ & $\begin{array}{l}\text { Attitude Toward } \\
\text { Complaining }\end{array}$ \\
\hline Consumer frustration 1 & 4.07 & 3.16 & 3.60 \\
\hline Consumer frustration 2 & 4.26 & 3.36 & 3.60 \\
\hline Consumer frustration 3 & 3.86 & 3.64 & 3.80 \\
\hline Consumer frustration 4 & 4.43 & 3.56 & 3.55 \\
\hline Information 1 & 4.22 & 4.59 & 3.76 \\
\hline Information 2 & 3.86 & 4.64 & 3.84 \\
\hline Information 3 & 3.90 & 4.69 & 3.87 \\
\hline Information 4 & 3.87 & 4.57 & 3.64 \\
\hline Information 5 & 2.86 & 4.52 & 3.80 \\
\hline 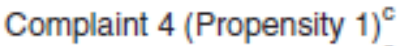 & 3.01 & 2.95 & 4.01 \\
\hline Complaint 5 (Propensity 2$)^{\mathrm{C}}$ & 2.56 & 2.21 & 3.50 \\
\hline Complaint 6 (Propensity 3$)^{\mathrm{C}}$ & 2.53 & 2.09 & 4.42 \\
\hline Complaint 7 (Propensity 4$)^{\mathrm{C}}$ & 2.65 & 2.72 & 3.59 \\
\hline Complaint 10 & 2.57 & 2.82 & 3.86 \\
\hline Complaint 1 (Negative 1$)^{b}$ & 2.56 & 3.48 & 3.48 \\
\hline Complaint 2 (Negative 2) & 2.52 & 3.64 & 3.55 \\
\hline Complaint 3 (Negative 3$)^{b}$ & 2.70 & 3.72 & 3.76 \\
\hline Complaint 8 (Negative 4$)^{b}$ & 2.34 & 3.46 & 3.63 \\
\hline Complaint 9 & 3.74 & 3.54 & 3.48 \\
\hline
\end{tabular}

a. Items and means presented in italics were rated significantly higher on the a priori dimension in comparison to the other items rated.

b. Denotes an item from the emergent complaint dimension labeled as negative attitude toward complaining. A separate matching definition was not used for these items.

c. Denotes an item from the complaint dimension renamed as propensity to complain when dissatisfied. 
Table 3. Item-Level Correlations

\begin{tabular}{|c|c|c|c|c|c|c|c|c|c|c|c|c|c|c|c|c|}
\hline & (1) & (2) & (3) & (4) & (5) & (6) & (7) & (8) & (9) & $(10)$ & (11) & (12) & (13) & (14) & (15) & (16) \\
\hline \multicolumn{17}{|l|}{ Propensity 1} \\
\hline Propensity 2 & $.45^{*+*}$ & & & & & & & & & & & & & & & \\
\hline Propensity 3 & $.50^{* * *}$ & $.32^{* * *}$ & & & & & & & & & & & & & & \\
\hline Propensity 4 & $.34^{* * *}$ & $.31^{* * *}$ & $.41^{* * *}$ & & & & & & & & & & & & & \\
\hline Negative 1 & -.13 & -.09 & $-.24^{* * *}$ & -.10 & & & & & & & & & & & & \\
\hline Negative 2 & -.09 & -.10 & -.09 & -.02 & $.35^{* * *}$ & & & & & & & & & & & \\
\hline Negative 3 & $-.13^{*}$ & -.07 & $-.16^{* *}$ & .00 & $.56^{* * *}$ & $.41^{* * *}$ & & & & & & & & & & \\
\hline Negative 4 & -.05 & -.06 & $-.20^{* *}$ & -.10 & $.50^{* * *}$ & $.39^{* * *}$ & $.48^{* * * *}$ & & & & & & & & & \\
\hline Information 1 & -.04 & -.05 & $-.14^{*}$ & -.09 & $.22^{* * *}$ & -.01 & $.18^{* *}$ & $.21^{* * *}$ & & & & & & & & \\
\hline Information 2 & -.08 & -.01 & $-.16^{* *}$ & -.10 & $.29^{* * *}$ & .07 & $.19^{* *}$ & $.24^{* * *}$ & $.41^{* * *}$ & & & & & & & \\
\hline Information 3 & -.02 & .00 & $-.14^{*}$ & -.06 & $.26^{* * *}$ & .03 & $.23^{* * *}$ & $.32^{* * *}$ & $.47^{* * *}$ & $.63^{* * *}$ & & & & & & \\
\hline Information 4 & -.07 & -.01 & $-.20^{* *}$ & $-.18^{* *}$ & $.17^{* *}$ & .04 & .03 & .04 & $.39^{* * *}$ & $.35^{\star * *}$ & $.39^{* *}$ & & & & & \\
\hline Information 5 & -.07 & -.08 & -.11 & -.05 & $.30^{* * *}$ & .01 & $.27^{* * *}$ & .10 & $.48^{* * *}$ & $.43^{* * *}$ & $.44^{* * *}$ & $.44^{* * *}$ & & & & \\
\hline Frustration 1 & .06 & -.03 & -.02 & .08 & $.13^{*}$ & $.19^{* *}$ & .09 & $.16^{*}$ & $.33^{* * *}$ & $.29^{* * *}$ & $.33^{* * *}$ & $.26^{* * *}$ & $.34^{* * *}$ & & & \\
\hline Frustration 2 & -.01 & -.01 & -.07 & -.01 & .12 & .08 & .08 & $.17^{* *}$ & $.41^{* * *}$ & $.32^{* * *}$ & $.37^{* * *}$ & $.31^{* * * *}$ & $.28^{* * *}$ & $.70^{* \star \star}$ & & \\
\hline Frustration 4 & .00 & -.06 & -.05 & -.05 & .09 & .13 & .03 & $.14^{*}$ & $.36^{* * *}$ & $.36^{* * *}$ & $.23^{* * *}$ & $.33^{* * *}$ & $.27^{* * *}$ & $.63^{* \star \star *}$ & $.65^{* * * *}$ & \\
\hline
\end{tabular}

Note: $N=230$ using listwise deletion.

${ }^{*} p<.05 .{ }^{* *} p<.01{ }^{* * *} p<.001$. 
Table 4. Scale-Level Descriptive Statistics and Correlations for Study Two

\begin{tabular}{lccccccc}
\hline Variable & $M$ & $S D$ & $(1)$ & $(2)$ & $(3)$ & $(4)$ & $(5)$ \\
\hline (1) Respondent sex & - & - & - & & & & \\
(2) Negative complaint attitudes & 2.35 & .72 & .08 & {$[.72]$} & & & \\
(3) Propensity to complain & 3.66 & .79 & .04 & $.18^{* *}$ & {$[.77]$} & & \\
(4) Information inadequacy & 4.12 & .67 & $.16^{*}$ & $.16^{*}$ & $.27^{* * *}$ & {$[.80]$} & \\
(5) Consumer frustration & 3.62 & 1.01 & .07 & .02 & $.17^{* *}$ & $.49^{* * *}$ & {$[.85]$} \\
\hline
\end{tabular}

Note: $N=230$ using listwise deletion; as a dummy variable no mean or standard deviation was calculated for respondent sex; and Cronbachs alpha is presented in brackets along the diagonal.

${ }^{*} p<.05 .{ }^{* *} p<.01 .{ }^{* * *} p<.001$ 


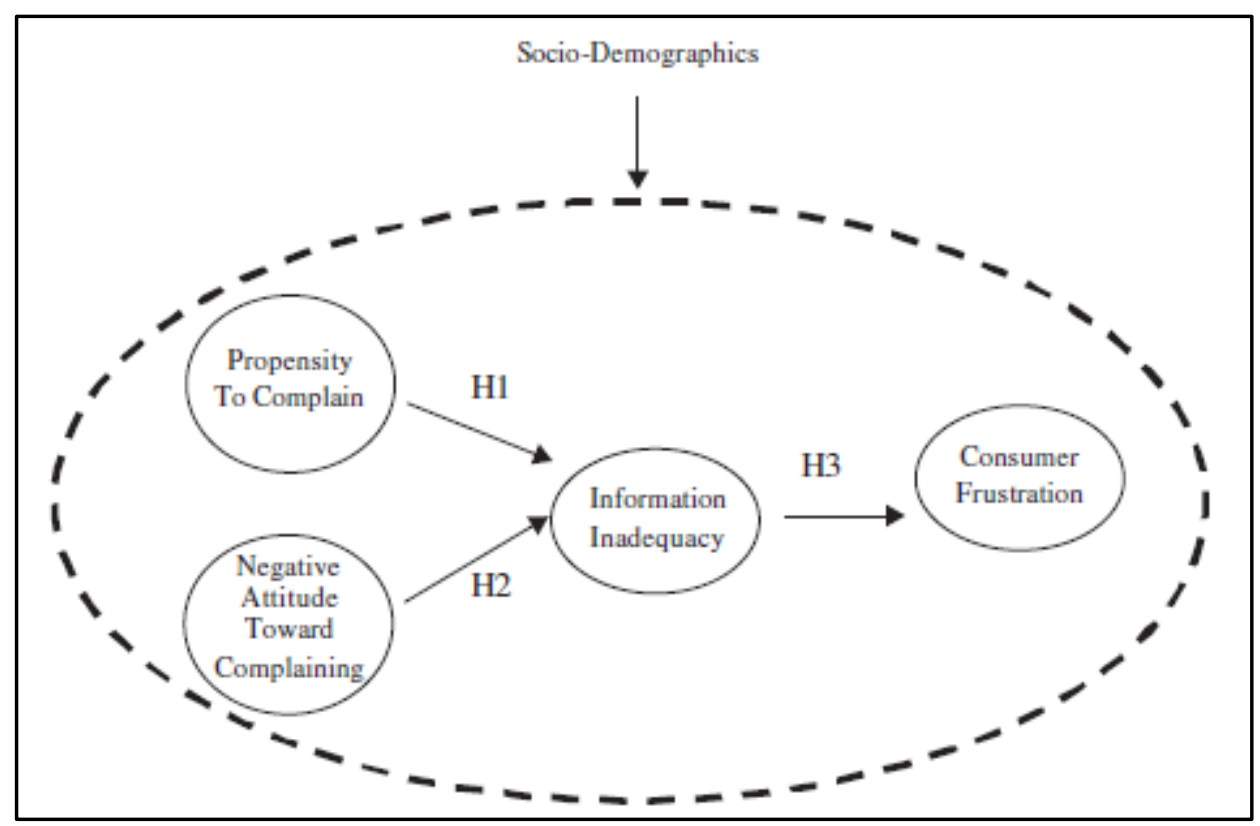

Figure 1. Hypothesized Model of Consumer Frustration 


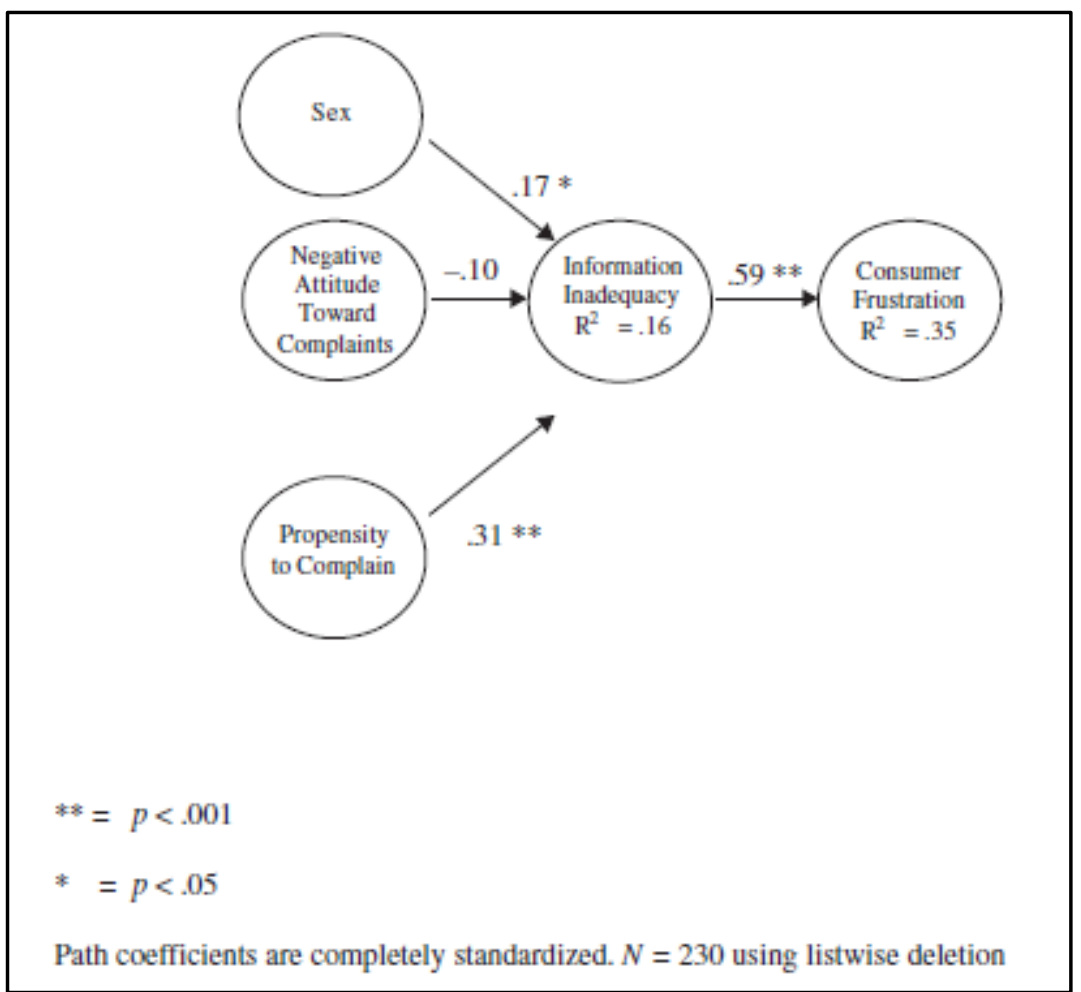

Figure 2. Test of the Model of Consumer Frustration 